\title{
A review and summary of the contents of biophysical reviews volume 8, 2016
}

\author{
Cris dos Remedios ${ }^{1}$
}

Received: 16 January 2017 / Accepted: 16 January 2017 / Published online: 7 February 2017

(C) International Union for Pure and Applied Biophysics (IUPAB) and Springer-Verlag Berlin Heidelberg 2017

In going into the new year of 2017, I thought it would be useful, in my role as Chief Editor, to revisit the activity of Biophysical Reviews (BREV) in the previous year. In 2016 BREV published four issues with a progressive increase in the number and length of the reviews. The following is a resume of these contributions.

Issue \#1 contained eight articles dealing with a range of interesting topics.

Navale and Paranjape (2016): This review described recent advances in glucose transporters that are needed for all living cells. These receptors are an essential component of all cells because they govern the intracellular supply of glucose for metabolism.

Nakano and Sugimoto (2016): This review dealt with structural and catalytic effects of organic solvents on DNA and RNA oligonucleotides. This is important because the findings can be used for the development of oligonucleotide-based technologies.

Inoue and Ishijima (2016): This manuscript described how carbon nanotubes can be used to monitor the ATPase activity of myosin molecules attached to carbon nanotubes, which can be directly heated without raising the temperature of heating the surrounding water, thus enabling evaluation of the direct effects of changes in activity of the myosin motor proteins as they interact with actin filaments. Nanobiophysics is becoming an increasingly "hot" topic and one for which Biophysical Reviews has appointed a specialist Editorial Board Member to help promote.

Cris dos Remedios

crisdos@anatomy.usyd.edu.au

1 Bosch Institute, University of Sydney, Sydney 2006, Australia
Ohto and Shimizu (2016): These authors highlighted current concepts on the effects of RNA and DNA binding on the Toll-like receptors. The extracellular membrane receptors are vital for the cellular response to invading pathogens.

Ikebe et al. (2016): This article reviewed the increased power of specialized sampling methods applied to molecular dynamics MD simulations under explicit solvent condition in predicting protein-binding partner interactions. The emphasis here was on practical applications of these enhanced MD simulations.

Rona et al. (2016): The authors discussed the most recent biophysical literature on the protein domain, PWWP, which binds to and recognises both DNA and histone methylated lysines present in the nucleosome (the fundamental unit of nuclear chromatin).

Sridharan and Ponnuraj (2016): Microbial surface components recognizing adhesive matrix molecules (MSCRAMMs) are found only on the surface of Gram-positive bacteria. They target extracellular proteins (for example, collagen and fibrinogen). The authors focused on isopeptide amide bonds between Lys, Asn and Asp residues on these proteins that help by providing resistance against host-defense mechanisms.

Issue \#2 contained 10 articles.

Spinozzi et al. (2016): This article reviewed the evaluation of structural and thermodynamic aspects of model proteins by the techniques of small-angle neutron scattering and differential scanning microcalorimetry. These methods can sense the changes in protein solvation.

Borges et al. (2016): Small angle X-ray scattering (SAXS) enables biophysicists to study protein domains. The authors reviewed the use of SAXS for studying molecular structure of chaperones (Hsp70 and Hsp90).

Germond et al. (2016): This erudite and eminently readable review provides the reader with an unusually clear explanation of why and how so many relatives of the familiar Green 
Fluorescent Protein (GFP) have been produced. The authors provide insight into new ways these fluorescent reporter proteins can be used to measure $\mathrm{pH}$, ion concentrations, redox indicators, membrane potential, temperature and pressure changes in molecular crowding.

Tokuda et al. (2016): Interactions between DNA and proteins can be detected using SAXS but solution contrast variation is required. This contribution reviews two strategies based on either (i) masking the protein contribution, or (ii) using of heavy atom isomorphous replacement in 25-base pair DNA.

Antosiewicz and Shugar (2016a, b): This open-access twopart article reviews the basic properties of tyrosine residues as studied by UV-visible spectroscopy. It is a scholarly work that shines a light on the theory and practice of studying tyrosines rather than the more common spectroscopic investigations that examine tryptophans.

Basso et al. (2016): This paper reviewed the use of Electron Spin Resonance (ESR) for studying protein-membrane interactions. First the authors discussed how ESR can be used to study lipid as it binds to a hydrophobic pocket on diogenase enzyme. They then switched the focus to study proteins and used EPR to study the interaction of model membranes with fatty acid binding protein.

Smith (2016): At my invitation, I asked Ian Smith, an eminent and indeed knighted Canadian biophysicist, to take the reader on a journey from pure biophysics research into the application of his research at the bedside. A open access pdf version of this article can be downloaded from the BREV website.

Seeto (2016): Then, by way of contrast, I invited a relatively young medical graduate, Reg Seeto, to write about his experiences half-way through his 40-year journey to the top of the pharmaceutical industry. It is both readable and insightful, and by way of a footnote, Reg recently informed me he has just taken the next big step up in his career pathway within big Pharma.

Special Issue \#3 contains 14 articles: This was a Special Issue devoted to DNA supercoiling, protein interactions and genetic function. The executive editors (Laura Finzi, Emory University) and Wilma Olson Rutgers University have tapped into their combined and deep experience in this field to assemble what is arguably the most authoritative collection of reviews on the topic.

Rather than attempt to summarise nuances of each article, I encourage interested readers in this complex subject to select what they need based on the following review titles.

The emerging role of DNA supercoiling as a dynamic player in genomic structure and function. Finzi and Olson (2016).

The regulatory role of DNA supercoiling in nucleoprotein complex assembly and genetic activity. Muskhelishvili and Travers (2016).

Controlling gene expression by DNA mechanics: emerging insights and challenges. Levens et al. (2016).
Recent insights from vitro single-molecule studies into nucleosome structure and dynamics. Ordu et al. (2016).

Effects of DNA supercoiling on chromatin architecture. Corless and Gilbert (2016).

Supercoiling biases the formation of loops involved in gene regulation. Finzi and Dunlap (2016).

DNA supercoiling during transcription. Ma and Wang (2016).

DNA supercoiling is a fundamental regulatory principle in the control of bacterial gene expression. Dorman and Dorman (2016).

The dynamic interplay between DNA topoisomerases and DNA topology. Seol and Neuman (2016).

Species-specific supercoil dynamics of the bacterial nucleoid. Higgins (2016).

Protein-induced DNA linking number change by sequencespecific DNA binding proteins and its biological effects. Leng (2016).

Insights into genome architecture deduced from the properties of short Lac repressor-mediated DNA loops. Perez and Olson (2016).

Protein/DNA interactions in complex DNA topologies: expect the unexpected. Noy et al. (2016).

Biophysical Reviews publications on DNA structure and function in other Issues that complement this Special Issue on DNA supercoiling. Editorial, dos Remedios (2016b).

Special Issue \#4 contained 18 articles: This Special Issue is entitled: Quantitative and analytical relations in biochemistry A Special Issue in Honour of Donald J Winzor's 80th birthday. By concentrating on the subject area of applied mathematics in biochemistry this Issue acted as a festschrift for celebrating the six-decade career of Donald J Winzor as a researcher and scientific mentor. The details are provided in that Issue's Editorial (dos Remedios 2016b) along with a series of short letters (Hall \& Harding 2016; Winzor 2016; Sawyer 2016; Minton 2016). The subject of each review was chosen by the author or authors to reflect an aspect of their inspirational time together and/or the things they learned as colleagues, or as students.

Here are the titles of the 18 articles in this issue:

Quantitative and analytical relations in biochemistry - A Special Issue in honour of Donald J Winzor's 80th birthday. (Foreword) Hall and Harding (2016).

Six decades of research in physical biochemistry. Winzor (2016).

A note on the career of Donald J. Winzor. Sawyer (2016).

Big ideas from "small science". Minton (2016).

Charge matters. Laue (2016).

A Hilly path through the thermodynamics and statistical mechanics of protein solutions. Wills (2016).

Assessing sedimentation equilibrium profiles in analytical ultracentrifugation experiments on macromolecules: from simple average molecular weight analysis to molecular weight distribution and interaction analysis. Harding et al. (2016).

Mineralization and non-ideality: on nature's foundry. Rao and Cölfen (2016). 
Aspects of protein-DNA interactions: a review of quantitative thermodynamic theory for modelling synthetic circuits utilising Lac1 and CI repressors, IPTG and the reporter gene lacZ. Munro et al. (2016).

Biosensor binding data and its applicability to the determination of active concentration. Karlsson (2016).

Protein-RNA interactions: structural biology and computational modeling techniques. Jones (2016).

NMR magnetization-transfer analysis of rapid membrane transport in human erythrocytes. Shishmarev and Kuchel (2016).

Molecular assembly and structure of the bacteriophage T4 tail. Arisaka et al. (2016).

Dissociative mechanism for irreversible thermal denaturation of oligomeric proteins. Chebotareva et al. (2016).

Dynamic light scattering: a practical guide and applications in biomedical sciences. Stetefeld et al. (2016).

Analytical methods for structural ensembles and dynamics of intrinsically disordered proteins. Schor et al. (2016).

Accounting for thermodynamic non-ideality in the Guinier region of small-angle scattering data of proteins. Scott (2016).

Measurement of amyloid formation by turbidity assayseeing through the cloud. Zhao et al. (2016).

How is Biophysical Reviews performing? In 2009 BREV commenced publication with 20 reviews published in four issues. In the following years the number of articles published per year remained fairly constant (see Table 1), and then in 2012 BREV published its first Special Issue (SI) on Computational Biophysics. The journal continued to publish one SI each year, and as their popularity increased the Editor increased it to two SIs per year in 2015-16. This decision increased the number and focus of reviews and was accompanied by an increase in the total published number of pages. In 2017, BREV plans to publish to six issues a year, of which four will be Special Issues.

Table 1 A table summarizing the number of articles and the size of the volumes published in Biophysical Reviews since the journal began in 2009

\begin{tabular}{llllllll}
\hline Year & Vol. & $\# 1$ & $\# 2$ & $\# 3$ & $\# 4$ & Revs & Pages \\
\hline 2009 & 1 & 6 & 5 & 5 & 4 & 20 & 185 \\
2010 & 2 & 5 & 4 & 5 & 4 & 18 & 189 \\
2011 & 3 & 5 & 5 & 5 & 5 & 19 & 217 \\
2012 & 4 & 5 & 6 & $12(\mathrm{SI})$ & 5 & 28 & 334 \\
2013 & 5 & 5 & $17(\mathrm{SI})$ & 5 & 4 & 31 & 345 \\
2014 & 6 & $14(\mathrm{SI})$ & 5 & 5 & - & 24 & 321 \\
2015 & 7 & $13(\mathrm{SI})$ & $12(\mathrm{SI})$ & 7 & 5 & 37 & 447 \\
2016 & 8 & 8 & 10 & $14(\mathrm{SI})$ & $18(\mathrm{SI})$ & 42 & 471 \\
\hline
\end{tabular}

(SI) indicates a Special Issue published on a defined theme and edited by specially appoint Special Issue Editors. The table shows that SIs contain more reviews that address a single theme
Ultimately publishing performance depends on more than just the number of articles and the number of pages. Citation rates of reviews are higher than primary reports and they rise gradually for $2-3$ years after publication.

Another important factor that affects publication success is the maintenance of the quality of the reviews. And finally, since the journal is half-owned by the International Union for Pure \& Applied Biophysics, there is an obligation for BREV to ensure the contents of Editorial Board and the articles it published reflect the International community.

Cris dos Remedios

Editor-in-Chief

January 15, 2017.

\section{References}

Antosiewicz JM, Shugar D (2016a) UV-Vis spectroscopy of tyrosine side-groups in studies of protein structure. Part 1: basic principles and properties of tyrosine chromophore. Biophys Rev 8:151. doi:10.1007/s12551-016-0198-6

Antosiewicz JM, Shugar D (2016b) UV-Vis spectroscopy of tyrosine side-groups in studies of protein structure. Part 2: selected applications. Biophys Rev 8:163. doi:10.1007/s12551-016-0197-7

Arisaka F, Yap ML, Kanamaru S et al (2016) Measurement of amyloid formation by turbidity assay - seeing through the cloud. Biophys Rev 8:385. doi:10.1007/s12551-016-0230-x

Basso LGM, Mendes LFS, Costa-Filho AJ (2016) The two sides of a lipid-protein story. Biophys Rev 8:179. doi:10.1007/s12551-0160199-5

Borges JC, Seraphim TV, Dores-Silva PR, Barbosa LRS (2016) A review of multi-domain and flexible molecular chaperones studies by smallangle X-ray scattering. Biophys Rev. doi:10.1007/s12551-016-0194-x

Chebotareva NA, Roman SG, Kurganov BI (2016) Dissociative mechanism for irreversible thermal denaturation of oligomeric proteins. Biophys Rev 8:397. doi:10.1007/s12551-016-0220-z

Corless S, Gilbert N (2016) Effects of DNA supercoiling on chromatin architecture. Biophys Rev 8(Suppl 1):51. doi:10.1007/s12551-0160242-6

Dorman CJ, Dorman MJ (2016) DNA supercoiling is a fundamental regulatory principle in the control of bacterial gene expression. Biophys Rev 8(Suppl 1):89. doi:10.1007/s12551-016-0238-2

dos Remedios CG (2016a) The evolution of Biophysical Reviews. Biophys Rev 8:1. doi:10.1007/s12551-015-0192-4

dos Remedios C (2016b) Biophysical Reviews publications on DNA structure and function that complement this special issue on DNA supercoiling. Biophys Rev 8(Suppl 1):157. doi:10.1007/s12551016-0213-y

Finzi L, Dunlap D (2016) Supercoiling biases the formation of loops involved in gene regulation. Biophys Rev 8(Suppl 1):65. doi:10.1007/s12551-016-0211-0

Finzi L, Olson WK (2016) The emerging role of DNA supercoiling as a dynamic player in genomic structure and function. Biophys Rev 8(Suppl 1):1. doi:10.1007/s12551-016-0214-x

Germond A, Fujita H, Ichimura T (2016) Design and development of genetically encoded fluorescent sensors to monitor intracellular chemical and physical parameters. Biophys Rev 8:121. doi:10.1007/s12551-016-0195-9

Hall D, Harding SE (2016) Measurement of amyloid formation by turbidity assay-seeing through the cloud. Biophys Rev 8:269. doi:10.1007/s12551-016-0227-5 
Harding SE, Gillis RB, Adams GG (2016) Species-specific supercoil dynamics of the bacterial nucleoid. Biophys Rev 8:299. doi: $10.1007 / \mathrm{s} 12551-016-0232-8$

Higgins NP (2016) Species-specific supercoil dynamics of the bacterial nucleoid. Biophys Rev 8(Suppl 1):113. doi:10.1007/s12551-0160207-9

Ikebe J, Umezawa K, Higo J (2016) Enhanced sampling simulations to construct free-energy landscape of protein-partner substrate interaction. Biophys Rev 8:45. doi:10.1007/s12551-015-0189-z

Inoue Y, Ishijima A (2016) Local heating of molecular motors using single carbon nanotubes. Biophys Rev 8:25. doi:10.1007/s12551015-0185-3

Jones S (2016) Protein-RNA interactions: structural biology and computational modeling techniques. Biophys Rev 8:359. doi:10.1007 /s12551-016-0223-9

Karlsson R (2016) Biosensor binding data and its applicability to the determination of active concentration. Biophys Rev 8:347. doi:10.1007/s12551-016-0219-5

Laue T (2016) Charge matters. Biophys Rev 8:287. doi:10.1007/s12551016-0229-3

Leng F (2016) Protein-induced DNA linking number change by sequence-specific DNA binding proteins and its biological effects. Biophys Rev 8(Suppl 1):123. doi:10.1007/s12551-016-0239-1

Levens D, Baranello L, Kouzine F (2016) Controlling gene expression by DNA mechanics: emerging insights and challenges. Biophys Rev 8(Suppl 1):23. doi:10.1007/s12551-016-0243-5

Ma J, Wang MD (2016) DNA supercoiling during transcription. Biophys Rev 8(Suppl 1):75. doi:10.1007/s12551-016-0215-9

Minton AP (2016) Big ideas from "small science". Biophys Rev 8:285. doi:10.1007/s12551-016-0225-7

Munro PD, Ackers GK, Shearwin KE (2016) Aspects of protein-DNA interactions: a review of quantitative thermodynamic theory for modelling synthetic circuits utilising LacI and CI repressors, IPTG and the reporter gene lacZ. Biophys Rev 8:331. doi:10.1007 /s12551-016-0231-9

Muskhelishvili G, Travers A (2016) The regulatory role of DNA supercoiling in nucleoprotein complex assembly and genetic activity. Biophys Rev 8(Suppl 1):5. doi:10.1007/s12551-016-0237-3

Nakano S, Sugimoto N (2016) The structural stability and catalytic activity of DNA and RNA oligonucleotides in the presence of organic solvents. Biophys Rev 8:11. doi:10.1007/s12551-015-0188-0

Navale AM, Paranjape AN (2016) Glucose transporters: physiological and pathological roles. Biophys Rev 8:5. doi:10.1007/s12551-0150186-2

Noy A, Sutthibutpong T, Harris SA (2016) Protein/DNA interactions in complex DNA topologies: expect the unexpected. Biophys Rev 8(Suppl 1):145. doi:10.1007/s12551-016-0241-7

Ohto U, Shimizu T (2016) Structural aspects of nucleic acid-sensing Tolllike receptors. Biophys Rev 8:33. doi:10.1007/s12551-015-0187-1
Ordu O, Lusser A, Dekker NH (2016) Recent insights from in vitro single-molecule studies into nucleosome structure and dynamics. Biophys Rev 8(Suppl 1):33. doi:10.1007/s12551-016-0212-Z

Perez PJ, Olson WK (2016) Insights into genome architecture deduced from the properties of short Lac repressor-mediated DNA loops. Biophys Rev 8(Suppl 1):135. doi:10.1007/s12551-016-0209-7

Rao A, Cölfen H (2016) Mineralization and non-ideality: on nature's foundry. Biophys Rev 8:309. doi:10.1007/s12551-016-0228-4

Rona GB, Eleutherio ECA, Pinheiro AS (2016) PWWP domains and their modes of sensing DNA and histone methylated lysines. Biophys Rev 8:63. doi:10.1007/s12551-015-0190-6

Sawyer WH (2016) A note on the career of Donald J Winzor. Biophys Rev 8:283. doi:10.1007/s12551-016-0224-8

Scott DJ (2016) Accounting for thermodynamic non-ideality in the Guinier region of small-angle scattering data of proteins. Biophys Rev 8:441. doi:10.1007/s12551-016-0235-5

Seeto RK (2016) Halfway through a 40-year decision: the journey of a medical graduate. Biophys Rev 8:195. doi:10.1007/s12551-0160203-0

Seol Y, Neuman KC (2016a) The dynamic interplay between DNA topoisomerases and DNA topology. Biophys Rev 8 (Suppl 1):101 doi:10.1007/s12551-016-0240-8

Seol Y, Neuman KC (2016b) The dynamic interplay between DNA topoisomerases and DNA topology. Biophys Rev 8:221 doi:10.1007/s12551-016-0206-x

Shishmarev D, Kuchel PW (2016) NMR magnetization-transfer analysis of rapid membrane transport in human erythrocytes. Biophys Rev 8: 369. doi:10.1007/s12551-016-0221-y

Smith ICP (2016) Biophysics to bedside - the transition. Biophys Rev 8: 193. doi:10.1007/s12551-016-0202-1

Spinozzi F, Mariani P, Ortore MG (2016) Proteins in binary solvents. Biophys Rev 8:87. doi:10.1007/s12551-016-0193-y

Sridharan U, Ponnuraj K (2016) Isopeptide bond in collagen- and fibrinogen-binding MSCRAMMs. Biophys Rev 8:75. doi:10.1007 /s12551-015-0191-5

Stetefeld J, McKenna SA, Patel TR (2016) Dynamic light scattering: a practical giude in biomedical sciences. Biophys Rev 8:409. doi:10.1007/s12551-016-0218-6

Tokuda JM, Pabit SA, Pollack L (2016) Protein-DNA and ion-DNA interactions revealed through contrast variation SAXS. Biophys Rev 8:139. doi:10.1007/s12551-016-0196-8

Wills PR (2016) A Hilly path through the thermodynamics and statistical mechanics of protein solutions. Biophys Rev 8:291. doi:10.1007 /s12551-016-0226-6

Winzor DJ (2016) Six decades of research in physical biochemistry. Biophys Rev 8:279. doi:10.1007/s12551-016-0222-x

Zhao R, So M, Maat H et al (2016) Measurement of amyloid formation by turbidity assay — seeing through the cloud. Biophys Rev 8:445. doi:10.1007/s12551-016-0233-7 